\title{
Educación, sociedad y nuevas tecnologías: una triada para la configuración del sujeto de hoy
}

\section{Education, society and new technologies - a triad for configuring today's individual}

\author{
Catalina María Sepúlveda Zapata ${ }^{1}$
}

La triada educación, sociedad y nuevas tecnologías, se aborda desde dos ejes, el primero corresponde a una reflexión teórica, base para la aplicación práctica del pensamiento contemporáneo; y el segundo, una postura crítica respecto al uso de las nuevas tecnologías en educación y la configuración de la sociedad.

Quintanilla (2005), define la técnica como sistemas de acciones humanas, lo cual sirve en la actualidad para establecer relaciones del cotidiano con un saber científico, que es propio de la modernidad, y que pienso puede transformar la realidad para adaptarla a nuestros deseos; donde no existen hechos sino interpretaciones. Éstas últimas, sustentadas por las redes como lo dice Castells (2002), como estructuras abiertas, capaces de expandirse sin límites integrando nuevos nodos mientras puedan comunicarse entre sí, es decir, siempre que compartan los mismos códigos de comunicación; generando sistemas dinámicos y abiertos, susceptibles a la innovación. En esa medida los sistemas técnicos, son redes, porque al establecer relaciones dinámicas, se propician condiciones ideales de fortalecimiento de los sistemas económicos, políticos y sociales.

En ese orden de ideas, Debray (2001), propone que un sistema técnico traduce las compatibilidades internas (redes, en la noción de Castells) de cada época al equipamiento de las sociedades, sin consideración de fronteras; un sistema cultural asegura, en el interior de una sociedad determinada,

Docente de apoyo programa talentos Secretaría de Educación de Medellín. 
las solidaridades existentes entre su pasado y su presente (proceso de transmisión); así la técnica se convierte en un elemento constitutivo del ser humano. Un ejemplo de ello fue cuando el hombre reconstruyó las relaciones entre ciencia y tecnología, a través de la investigación en la industria militar, a partir de la bomba de Hiroshima.

Un desarrollo tecnológico acosta de todo, incluso del bienestar humano, si se toma la idea de que sólo los países "desarrollados" (mis comillas) pueden acceder a sistemas tecnológicos. Los procesos de innovación tecnológica obligan a todos los países a ordenar sus procesos y a desarrollar metodologías, en beneficio de la eficiencia, concepto que combina la eficacia con la minimización de costos para alcanzar los efectos buscados. Luego, estas mejoras estimulan el crecimiento con base en la participación de esta parte del mundo en los procesos productivos que aportarían al crecimiento económico, creando condiciones que conduzcan a un cambio estructural, basados en una renovación tecnológica que genere un incremento de la productividad.

Así, la riqueza, la tecnología y el bienestar, se refuerzan en un círculo virtuoso de progreso. Vega Cantor (2007), afirma que en el instante en que se impulsa una determinada tecnología origina modificaciones y tiene consecuencias que afectan directamente a la sociedad y a la naturaleza. Claro que hay modificaciones, debe haberlas, puesto que la tecnología implica un sistema complejo de relaciones sociales. Jerry Mander, citado por Vega Cantor ( 2007), lo afirma cuando dice que no se debe juzgar la tecnología por las ventajas concretas para el sujeto. Se debe procurar analizar los efectos holísticamente. La cuestión fundamental no es sí beneficia al sujeto concretamente, sino a quién beneficia más y con qué finalidad.
La tecnología tiene efectos colectivos, por más que se piense en forma individual. Cada vez es mayor el sentido de desarraigo que se siente por lo que no nos involucra. Si se piensa el desarrollo tecnológico como un sistema de nodos interconectados, como lo dice Castells (2002), los efectos negativos tenderán a desaparecer.

Entonces se piensa a la tecnología como forma de poder sobre el mundo natural y sobre los sujetos. La ciencia y la tecnología no tienen un carácter neutral puesto que su desarrollo responde al surgimiento de la sociedad capitalista. Efectivamente, la existencia misma de este sistema se vincula directamente a la innovación sistemática de sus fuerzas productivas y al desarrollo permanente de la ciencia como fundamento de la producción técnica. Se sigue pensando que esto obedece a que la prioridad radica en la reproducción técnica por encima de la reproducción social y natural; por lo tanto nos vamos a encontrar siempre en la ciencia y la tecnología con objetos tan contradictorios como el propio capital: aportan vida y muerte a la vez. $\mathrm{Al}$ analizar las transformaciones tecnológicas, es imperante discernir sobre su efecto en los sistemas de producción y trabajo; al mismo tiempo considerar el impacto social en términos capitalistas.

La tecnología se ocupa de la acción humana sobre cosas y personas dando poder sobre cosas y seres humanos, y no todo poder es bueno para todos. La creación de riqueza puede tener efectos negativos. Los riesgos ecológicos, nucleares, químicos y genéticos (biotecnología), muchas veces intangibles y globales, acompañan a los beneficios del desarrollo y afectan a la sociedad moderna.

Resulta obvio que los avances tecnológicos permiten a la humanidad progresos irrenunciables, 
pero debemos tener en cuenta los precios a pagar y reflexionar si podemos evitar efectos negativos. La tecnociencia es un instrumento de dominio y transformación de la naturaleza y de la sociedad, por eso de ella se espera un avance en el control de la naturaleza, una mejora en la calidad de vida; sin embargo parece beneficiar sólo a determinados grupos sociales. De suerte que es el deseo de enriquecimiento y poder, más que el de saber, el que hoy impone a la ciencia y a la técnica el imperativo de mejorar sus actuaciones y la realización de sus productos. Dejando de lado las razones humanitarias, se le da al desarrollo de la ciencia un sentido a favor del incremento del poder económico y político.

El nuevo procesamiento de la información ha generado, una nueva civilización, una nueva cultura, se unen nuevos lugares, nuevos ámbitos de la vida individual y colectiva. Castells (2002), habla que la globalización y la informacionalización, instituidas por las redes de riqueza, tecnología y poder, están transformando nuestro mundo, están ampliando nuestra capacidad productiva, nuestra creatividad cultural y nuestro potencial de comunicación. Por lo tanto, las nuevas técnicas de comunicación por mundos virtuales replantean de manera diferente los problemas del vínculo social. En suma, la hominización, el proceso de surgimiento de la especie humana no ha finalizado, incluso como diría Pierre Lévy, parece acelerarse brutalmente.

Acelerados por agentes sociales, como parte de un proceso técnico, como si no tuvieran otro rostro diferente al de la información, al de la virtualidad permanente. Virtualidad que en palabras de Lévy (1995), no tiene que ver con aquello que nos dicen los medios de comunicación. No es un mundo falso o imaginario. Por el contrario, la virtualización es la propia dinámica del mundo común, aquello por lo que compartimos una realidad y un conocimiento.

Realidad que se ha reconfigurado con la llegada del internet, base material y tecnológica de la sociedad red. Es una infraestructura tecnológica y un medio organizativo que permite el desarrollo de una serie de nuevas formas de relación social que no tienen su origen en internet, que son fruto de una serie de cambios históricos pero que no podrían desarrollarse sin internet. Una sociedad cuya estructura social está construida en torno a redes de información.

El conocimiento del potencial de internet y sus aplicaciones en el ámbito educativo se convierte en una premisa si se pretende integrar curricularmente este recurso en los procesos de aula. Sólo así podremos promover una adecuada explotación didáctica de internet, en la que tanto alumnos como profesores, se sirvan de la red para actualizar su conocimiento o acceder a información nueva y de primera mano, comunicarse, expresar ideas y compartir experiencias, desarrollar proyectos colaborativos, etc.

De otro lado, mirar al internet como la pieza faltante de un rompecabezas social, donde los problemas de salud, vivienda y educación, por citar sólo algunos, están en crecimiento, es quitar el compromiso social que tienen los Estados. Referir todo a la acción de un sistema informacional, carece de significación y aplicación, aunque la mayoría de la organización social está construida en torno a redes de información. Si bien es cierto, que los procesos de globalización están demandando nuevas interacciones y configuraciones sociales, no se puede dejar a un lado los problemas reales de 
la sociedad; como dice Lévy, descubramos la cuestión real de ellos, pongamos los límites en la realidad.

Los mensajes que circulan hoy son distintos, la información no se basa sólo en un intercambio de mensajes, sino en la interpretación y significación de éstos. Debray (1997), manifiesta que la palabra comunica y que transmitir es organizar, construir territorio, solidificar un conjunto y trazar fronteras. Los nuevos procesos de socialización y el intercambio de información, dan como resultado un proceso de transmisión y en el sentido que lo plantea Debray (1997), no tiene las características del mensaje inicial. Para impulsar una idea, cualquiera que sea, en primer lugar hay alterarla o deformarla para volverla a formar de otro modo. Se tejen nuevos territorios, y el aquí y el ahora, no será, después de un proceso de transmisión informacional, el mismo aquí y ahora que significan las nuevas sociedades.

Sociedades mediadas por los mitos informáticos, como lo dice Vega Cantor (2007), mitos que vienen acompañados de la ruptura de los nexos personales y la comunicación real entre las personas de carne y hueso. Se elimina el contacto real, se crean islas cognitivas, compras mediadas por comercio.com, relaciones afectivas que se gestan a través de una pantalla de computador. Es cierto que se generan nuevas interacciones y realidades sociales, que si no se canalizan correctamente se convierten en virus imaginarios (como lo propuse en la relatoría anterior). Lo que se gana, dice Fisher citado por Vega Cantor (2007), en distancia a través de la tecnología, se pierde en proximidad psicológica.

El mundo real como lo muestra Vega Cantor, no se reduce al ciberespacio. En el texto se plantea que la memoria humana se reduce a la memoria de las máquinas. Si esto se contextualiza, se podría estar perdiendo la posibilidad de transmisión de herencia viva y de historia.

La postura que Renán Vega Cantor, plantea en su texto sobre la educación y las nuevas tecnologías, la comparto cuando habla de impregnar de realidad a la escuela y de capacitar a sus maestros. En esa medida la escuela no debe ser ajena a los nuevos procesos culturales y globales del mundo. "Adaptarse" no significa rebajarse ni perder su esencia. Martín Barbero (2007) decía en relación a esto, que la escuela está dejando de ser el único lugar de legitimización del saber; puesto que hay una multiplicidad de saberes que circulan por otros canales, difusos y descentralizados. Es esta diversificación y difusión del saber, fuera de la escuela, uno de los retos más fuertes que el mundo de la comunicación plantea al sistema educativo. No se puede pensar en "satanizar" las nuevas tecnologías, lo que debe hacerse es canalizar los sistemas informáticos y crear políticas públicas para que todos tengan acceso a los sistemas de comunicación e información. Sí, las nuevas tecnologías de la información no han solucionado muchos problemas educativos, sobre todo el de cobertura. Pero no se puede tirar la toalla. Vega Cantor nos muestra un panorama desolador, puede ser real; pero si se invierte más en proyectos educativos que tengan como referentes las nuevas tecnologías, el panorama puede cambiar. Se debe invertir en todo: infraestructura, capacitación docente, adecuación de bibliotecas, aulas digitales, etc. Todo hace parte de procesos de mejoramiento, que tiene que llevar a cabo el sistema educativo Colombiano.

Otro problema ańadido (en eso hay que tener sentido de realidad) es que mientras las tecnologías provocan la ilusión de dirigirnos hacia la aldea global, los avances siguen sin 
estar al alcance de todos. Por un lado podemos hablar de la división digital y exclusión social entre los sectores sociales con fácil acceso a este universo electrónico frente a otros que no lo tienen. Si estamos convencidos de que el gran objetivo (ideal) de estas nuevas tecnologías es facilitar y dar soporte a productos y servicios que permitan mejorar la calidad de vida humana a través de la información, facilitando el acceso global e igualitario a ésta desde cualquier punto, y consolidando y creando núcleos de acercamiento de los grupos sociales entre sí; sin embargo el uso de nuevas tecnologías de la información y la comunicación puede tomar un camino exclusivamente productivista, dividiendo aún más las estructuras sociales existentes, de tal forma que pudiéramos vernos inmersos también en una nueva clasificación del mundo, atendiendo, no a aspectos geográficos o políticos, sino tecnológicos.

La información que se obtiene en internet sólo es efectiva, como lo afirma Vega Cantor (2007), si se tiene una información básica que permita relacionarse críticamente con ese cúmulo de información que hay en la red; entonces desde las escuelas se deben tomar posturas para desarrollar en los estudiantes habilidades de pensamiento como el juicio crítico; no hay que dejarlo todo a manos de la enciclopedia del mundo, para eso están los docentes de carne y hueso(como lo nombra Vega Cantor), para poner en juego, las reglas implícitas e explícitas en los procesos de interacción.

En esos procesos de interacción, enseñar, según José Luis Pardo (2004), sería, en ese caso, ayudar a otros a hacer explícito un saber que implícitamente ya poseen. La solución de la imposibilidad reside en que sólo es posible aprender (explícitamente) porque ya se sabía (implícitamente). No hay transición posible (pues en la idea misma de esa transición reside la imposibilidad o la contradicción) de la ignorancia al saber, como no la hay de la nada al ser. Por lo tanto, el aprendizaje siempre se da que existe el Otro que explicite lo implícito.

El aprender es posible porque está el Otro( independiente de los contextos de interacción), donde los instrumentos cognitivos y signos que constituyen herramientas culturales para la construcción de la persona, configuran al Otro como el lugar que formatos de interacción crean; y desde la caracterización de la escuela se asume que, desde la concepción de alumno, se aprende a ser sujeto como el Otro del maestro que interactúa para darle configuración a ésta, desde momentos dialécticos(aquí se evidencia ese tercer lugar planteado por Michel Serres en el paso del Noroeste) para transformar el contexto. Un contexto con juegos y reglas, con situaciones implícitas y explícitas, con actos y con potencias; donde el agente principal es el sujeto que aprende, que al pedir explicaciones porque no entendía, se vale de su carga interna para darle sentido desde la interacción a lo que aprende, donde las reglas inscritas en nosotros son las marcas de lo que se hacía mientras se aprendía. La memoria sirve de engranaje entre ese recuerdo implícito y la explicitación del acto que lo conlleva, entre el hecho y la percepción, entre lo que se aprende y se sabe. Aquí muestro nuevamente, que las interacciones a través de las intersubjetividades, configuran al sujeto de hoy. Interacciones que exigen del maestro mayor compromiso, iniciando con su capacitación, poner de manifiesto su papel en los procesos de formación.

El conocimiento sigue siendo la acción de pensar, no porque se utilicen las nuevas tecnologías, los procesos reflexivos se dejan a un lado, son nuevas reflexiones; y no como lo dice Vega Cantor (2007), 
cúmulo de información que supera la capacidad individual de cada persona. Lo repito, existen nuevas interacciones, nuevos espacios y tiempos. Nunca un computador podrá reemplazar el espacio y tiempo de un ser humano.

Es la era de Frankenstein, pero no como la muestra Eduardo Galeano, de monstruos que ni siquiera sabemos que comemos; sino como un conjunto de intersubjetividades que se tejen de realidades multiculturales. Por lo tanto, la personalidad humana no se desdibuja sino que se transforma. Mario Bunge (2007) dice, los flujos de información forman parte de las relaciones sociales que mantienen y transforman las sociedades; como un proceso de transmisión en palabras de Régis Debray, donde el conocimiento sirve para reestructurar realidades. Y así lo enuncia Michel Serres: el conocimiento se ha convertido en la nueva infraestructura.; que según lo universal de la cultura tendría que ver con la relación del individuo y el colectivo. Una relación que se enmarca por las nuevas configuraciones que ha traído consigo el mundo digital. Generándose así, una extensión de esa infraestructura.

Es una nueva sociedad, es virtual. Desde el surgimiento de la especie humana, se ha hablado de virtualización. La virtualización acarrea siempre una materialización de los pensamientos, y no es más que el surgimiento de la herramienta para el desarrollo de la humanidad y de su proceso de transmisión para concebirla como ahora lo hacemos.

En la constitución de la humanidad se tienen tres procesos que son vitales, enunciados por Lévy (1995), y que su vez enmarcan asertivamente su desarrollo: el lenguaje, la técnica y las relaciones sociales; por el lenguaje se transmiten la emoción y los pensamientos; por la técnica la acción y por las relaciones sociales la construcción del colectivo. Es así como la construcción social pasa por la virtualización, ese aquí y ahora, esa desterritorialización que abra los espacios para que los individuos se construyan a partir de la organización de secuencias, de sus correspondencias; y de la combinación de éstas, un trívium de signos, de cosas y de seres. La virtualización en realidad expresa una continuidad en el largo proceso de la hominización; si la humanidad pasa por estos tres procesos: el desarrollo de los lenguajes, la abundancia de las técnicas y la creciente complejidad de las instituciones; está virtualizando su desarrollo y crecimiento.

Por lo que se refiere al lenguaje, crea la capacidad de distanciarse del presente y tomar perspectivas de pasado o de futuro(nuevas interacciones), es la herramienta tanto del razonamiento como de la imaginación, abriendo caminos para un aprendizaje rápido y una celeridad y potencia de pensamiento inéditas.

Se muestra al lenguaje como el instrumento materializador de la realidad y que la virtualiza poniendo al ser humano en un aquí y ahora, además que se abre la posibilidad de potenciar nuestra inteligencia gracias a los mecanismos que incrementan la velocidad, el volumen de contenidos y la interconexión entre humanos pensantes. Nos encontramos en uno de esos momentos críticos en la historia, una encrucijada en la que se decide el camino en el que la humanidad ha de recorrer en el futuro, más allá de lo meramente tecnológico y económico; se trata más bien de aprovechar el empuje de las nuevas tecnologías para plantear un proyecto de civilización centrado en los colectivos inteligentes, uno de esos momentos críticos en la historia, que puede sucumbir a la exclusión y banalización. 
Se puede pensar que las más recientes transformaciones educativas suelen ser relacionadas unívocamente con la revolución tecnológica de las comunicaciones. Sin embargo, la complejidad de los acontecimientos que afectan a la educación trasciende la circunstancial irrupción de los nuevos instrumentos y de sus posibilidades pedagógicas.

Resultaría simplista asociar de manera unilateral los cambios económicos y políticos con los avances en las comunicaciones. Igualmente, no puede aceptarse que las consecuencias de esos y otros cambios sobre los sistemas educativos puedan explicarse de forma mecánica y lineal como producidos por una sola causa. La respuesta a las preguntas sobre el origen de las transformaciones educativas debe buscarse, al menos, en otros cuatro ámbitos y en los cambios que se están produciendo en ellos.

Primero, en lo político. Los cambios que se están operando en las estructuras de los Estados obligarían a redefinir el lugar de lo educativo en la sociedad. Segundo, en las formas de organización social que están emergiendo y que producirían modificaciones en las propias prácticas educativas. Tercero, en la cultura de las nuevas formas de comunicación social y de producción del conocimiento, pero sobre todo de los imaginarios desde los que interpretamos dichas prácticas. Por último, en la economía, donde se están creando formas de producción e intercambio de bienes y servicios, con la consecuente modificación en las demandas realizadas a los sistemas educativos.

Por último, los cambios son inevitables; se resiste quien no quiere el cambio, puesto que conlleva un esfuerzo adicional de puesta al día en cuestiones didácticas y científicas; se resiste quien no está acostumbrado a trabajar en equipo o no quiere o no sabe; se resiste quien se siente amenazado por los cambios que produce lo desconocido; se resiste quien se conforma con la situación que le viene dada; se resiste quien es incapaz de cambiar sus hábitos y sus seguridades, y se resiste quien ve en peligro privilegios y derechos adquiridos; pero también se resiste quien, animado por el proyecto educativo, no encuentra ni los medios ni los apoyos institucionales ni el equipo de trabajo; se resiste quien encuentra que la oferta le queda corta después de tanto afán y de tanta ilusión puesta en cambiar la educación, y se resiste quien desconfía de tanta promesa cuando se toma conciencia de que las condiciones para llevarla a cabo no están dadas y se resiste quien estando abierto al cambio se ve sorprendido por un discurso que no tiene el poder transformador de la palabra que nace de la experiencia vivida en la escuela. 


\section{Bibliografía}

Bunge, M. (2007). Información+evaluación=co nocimiento. En C. R. Vega, Un mundo incierto, un mundo para aprender y enseñar (pág. pp. 293). (Volumen 1l). Bogotá, Colombia: Nomos.

Castells, M. (2002). La Era de la información. Economía, sociedad y cultura. (Tomo l). México, D.F.: Siglo Veintiuno Editores.

Castells, M. (2002). La Era de la información. Economía, sociedad y cultura. (Tomo ll). México, D.F.: Siglo Veintiuno Editores.

Debray, R. (2001). Introducción a la mediología. Barcelona, España: Paidós.

Debray, R. (1997). Transmitir. Buenos Aires, Argentina: Manantial.

Lèvy, P. (1995). ¿Qué es lo virtual? Barcelona, España: Paidós.
Martin, B. J. (2007). Tecnicidades, identidades, alteridades: desubicaciones y opacidades de la comunicación en el nuevo siglo. En De Moraes, Sociedad Mediatizada ( pp. 75). Barcelona, España: Gedisa.

Pardo, J. L. (2004). La regla del juego: Sobre la dificultad de aprender filosofía. Barcelona, España: Galaxia Gutenberg.

Quintanilla, M. (2005). Un Enfoque Filosófico y otros ensayos de filosofía de la tecnología. México: Fondo de cultura económico.

Vega, C. R. (2007). Un mundo incierto, un mundo para aprender y enseñar: las transformacionesmundiales y su incidencia en la enseñanza de las ciencias sociales. (Volumen 2). Bogotá, Colombia: Nomos 